\title{
A COMPARISON OF TWO COMMON SNIPE NESTS
}

\author{
by Jack Lane, Brandon, Manitoba
}

On June 25, 1964, while wading Douglas Marsh at a point 12 miles east of Brandon, I found a nest of the Common Snipe (Capella gallinago delicata) containing two eggs. The following day I was so fortunate as to locate a second nest of the species, this one holding three eggs. Since this meant that both nests would attain their full clutches on June 27, an excellent opportunity was presented for a comparison of incubation data.

The distance between the nests was one-quarter mile, with Nest No. 1 lacated just over 400 yards from the south edge of the marsh, while Nest No. 2 was situated to the southeast, 100 yards from the south shore. The type of habitat for both nests was semi-quaking bog, interspersed with small clumps of willow and the entire area covered by a heavy stand of sedge grass. The two sets of eggs featured entirely different groundcolors, those in Nest No. 1 being an extremely dark shade, almost a blackish-green, while the other set was quite greyish-olive in color. At no time did a bird flush directly from either nest until after incubation had begun. I believe these nests were second broods as I had found a nest on June 14 with the young dried and out of the nest. That was undoubtedly a first brood.

Repeated visits were made to each nest during incubation, and when reaching the location of Nest No. 2 on July 11, I found that a herd of cattle had ventured out into the marsh and thoroughly trampled the entire nest-area. Even my two nest markers were gone, and I had great difficulty in finding the nest. The Snipe finally flushed from beneath my feet, and it was apparent that the cattle had given the two birds a bad time of it. Most of the concealing cover was gone from around the nest, which had lost all identity as a nest, being now a mere shallow hollow with no vestige of lining. One egg had the large end crushed in. I was certain that this set would not hatch out, believing that the sitting bird had probably been kept away from the eggs long enough for the embryos to cool. On visiting the nests on July 14 I found Nest No. 1 had hatched out three eggs on that, the 18th day, while the fourth egg held a dead, fully-formed chick. The three good eggs in Nest No. 2 were still intact, with no sign of any chipping, and I was more certain than ever that the embryos had died. Returning the following day, I found one egg had hatched and the parents were distracing in a spectacular manner, fluttering in zig-zag fashion across the sedge with tails fully fanned and the one bird emitting hoarse, gasping sounds. I believe this was the hen. The next day only the crushed egg remained in the nest.

Assuming that incubation started the morning the final egg was laid in each nest, and taking 6:00 a.m. as a starting time, Nest No. 1 had an incubation period of 17 days, plus hours. Nest No. 2 had a period of 19 days, plus hours. A. C. Bent (Bulletin 142, United States National Museum) gives the incubation period of this species as 18-20 days, and other studies agree that there is a defirite variation in hatching times. Despite this, I cannot help believing that the cattle intrusion contributed to the delay in the hatching of Nest No. 2.

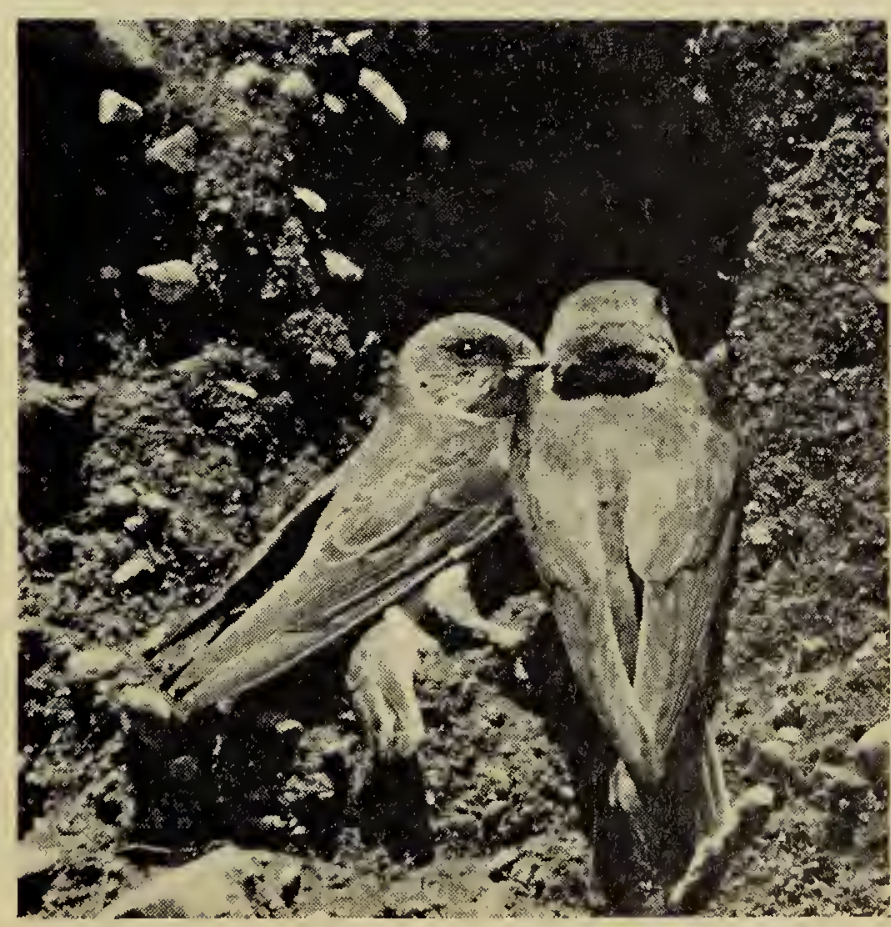

Photo by W. Yanchinski, Naicam

Bank Swallows at nest cavity 